\title{
GRUPOS COLABORATIVOS: A FORMAÇÃO DE PROFESSORES DO ATENDIMENTO EDUCACIONAL ESPECIALIZADO
}

\author{
Eromi Izabel Hummel ${ }^{1}$, Anna Karina Varoni², Déborah Cristina Málaga Barreto ${ }^{3}$
}

\begin{abstract}
Resumo: As atuais políticas educacionais brasileiras reforçam que os alunos com deficiências físicas, visuais, auditivas, intelectuais, transtorno global de desenvolvimento e altas habilidades, recebam o Atendimento Educacional Especializado (AEE) nas escolas regulares de ensino. Conforme a Resolução 002/2009, que trata das diretrizes do AEE, o professor responsável por esta atividade deve ter sua formação específica nesta área de atuação, pois cabe a ele um conjunto de atribuições que requer diversos conhecimentos. Visando a formação continuada dos professores, a Secretaria Municipal de Educação de Londrina, Estado do Paraná, iniciou no ano de 2017 uma proposta de formação em grupos colaborativos, tendo em vista que esta abordagem "reconcilia duas dimensões da pesquisa em educação, construção dos saberes e a formação contínua dos professores” (Ibiapina, 2008, p. 21). A metodologia colaborativa, propõe uma relação dialética entre teoria e prática, e reforça a importância de os professores constituírem grupos de estudo para que no coletivo adotem uma postura investigativa, questionadora e transformadora em suas práticas, na medida que a formação se volta para a resolução das dificuldades enfrentadas, e principalmente, aqueles vivenciados durante o AEE. Participaram da formação 69 professores que prestam o AEE em salas de recursos multinacionais. A formação constituiu de três etapas: 1) Diagnóstico das demandas; 2) Encontros teórico-reflexivo; 3) Avaliação dos resultados. As demandas foram registradas pelas professoras participantes durante um encontro pedagógico, que apontaram como necessidade de aprofundamento os seguintes temas: Deficiências e transtornos, Intervenção pedagógica, Avaliação, Altas Habilidades, Alfabetização e Matemática. Os resultados finais da formação foram apresentados em forma de seminário. Evidenciou-se a relação teoria e prática nos trabalhos expostos pelas professoras participantes. Acreditase que este modelo de formação contribuiu, significativamente, na construção de novos saberes e reflexões na atuação prática das professoras durante o atendimento educacional especializado.
\end{abstract}

Palavras-chave: Atendimento educacional especializado. Formação de professores. Trabalho colaborativo. Educação inclusiva.

1 Licenciada em Pedagogia, Mestre em Educação - Universidade Estadual de Londrina. Doutora em Educação - Universidade Estadual Paulista - Campus Marília. Professora Adjunta do Curso de Pedagogia - Universidade Estadual do Paraná - Campus Apucarana.

2 Graduada em Ciências Biológicas pela Universidade Estadual de Londrina. Especialista em Educação Especial. Psicopedagoga da rede municipal de educação de Londrina.

3 Licenciada em Pedagogia, Mestre em Educação - Universidade Estadual de Maringá. Psicopedagoga da rede municipal de educação de Londrina. 


\title{
COLLABORATIVE GROUPS: THE TRAINING OF TEACHERS OF SPECIALIZED EDUCATIONAL SERVICES
}

\begin{abstract}
Current Brazilian educational policies reinforce that students with physical, visual, hearing, intellectual, global developmental disorders and high skills receive the Specialized Educational Assistance (AEE) in regular schools. According to Resolution 002/2009, which deals with the ESA guidelines, the teacher responsible for this activity must have in its specific training in this area of action, because it is a set of assignments that requires different knowledge. Aiming at the ongoing training of teachers, the Municipal Education Department of Londrina, State of Paraná, Brazil, started in 2017 a proposal for training in collaborative groups, considering that this approach "reconciles two dimensions of research in education, construction Knowledge and the continuous training of teachers" (Ibiapina, 2008, p.21). The collaborative methodology can also ensure a dialectical relationship between theory and practice, and reinforce the importance of teachers forming study groups so that the collective adopts an investigative, questioning and transforming attitude of their practices, as the formation turns to The resolution of the difficulties faced, and especially those experienced during the ESA. Sixty-one teachers who provide ESA in multinational resource rooms will participate in the training. The training will consist of three stages: 1) Diagnosis of demands; 2) Theoretical-reflective meetings; 3) Evaluation of results. Considering that the training is in progress, the results of Step 1 will be presented. The demands were registered by the participating teachers during a pedagogical meeting, which pointed out as a need to deepen the following themes: Deficiencies and disorders, Pedagogical intervention, Assessment, High Abilities, Literacy and Mathematics. The final results of the training were presented in the form of a seminar. The relation between theory and practice in the works presented by the participating teachers was evidenced. It is believed that this training model contributed, significantly, in the construction of new knowledge and reflections in the practical performance of the teachers during the specialized educational service.
\end{abstract}

Keywords: Specialized educational assistance. Teacher training. Collaborative work. Inclusive education.

\section{INTRODUÇÃO}

A formação de professores tem sido foco de atenção devido a sua importância. Sendo assim, pensar nessa formação de professores para o AEE é essencial. Em um breve recorte teórico, da literatura relativa ao tema, ou seja, pesquisas que debruçaramse em entender a formação dos professores para a inclusão de alunos com necessidades educacionais especiais (NEE), podem ser destacados por Vitaliano e Manzini (2010, p.59). Esses autores, por meio de relato de pesquisa realizada com professores do ensino regular, a respeito da formação recebida para a inclusão de alunos com necessidades educacionais especializadas afirmam que estes profissionais encontram-se despreparados para incluir alunos com deficiências, se for considerada a forma como isso deveria ser feito. Dentre os fatores apontados como causa, ressaltou-se a falta de preparo, pouca carga horária e disciplinas com conteúdos teóricos sem oportunidades de desenvolvimento de práticas pedagógicas e, ainda, a concepção de homogeneidade e de aluno ideal no âmbito educacional.

A formação de professores deveria voltar-se para a compreensão de que o ambiente escolar se constitui por indivíduos heterogêneos que necessitam de ações pedagógicas adequadas e também heterogêneas. Sendo assim, conhecer as especificidades dos 
alunos com necessidades especiais é essencial no sentido de formar o professor para identificar e compreender as características das deficiências e possibilitar experiências de aprendizagem adequadas ao aluno.

A atuação em uma sociedade em que muito se discute sobre a Educação Inclusiva requer uma formação adequada. $\mathrm{O}$ ensino e aprendizagem dos docentes em seus processos de formação, durante sua atuação enquanto profissionais tem proporcionado constantes debates e reflexões (SCHÖN, 1997; MAGALHÃES, 2004; AZANHA, 2006; MIZUKAMI et al., 2006; PERRENOUD, 2007; TARDIF, 2007).

A formação inicial deve embasar os estudantes, não apenas teoricamente, mas com atividades práticas, para que compreendam as maneiras como os alunos desenvolvem suas atividades em sala de aula (HUMMEL, 2007). O debate acerca da formação inicial forneceu subsídios que revelam a preparação dos futuros professores com lacunas que precisam ser reavaliadas para o desenvolvimento de ações inovadoras na formação. Ibermón (2000, p. 66) afirmando que os conteúdos curriculares devem dotar-se de

[...] uma bagagem sólida nos âmbitos científico, cultural, contextual, psicopedagógico e pessoal que deve capacitar o futuro professor ou professora a assumir a tarefa educativa em toda sua complexidade, atuando reflexivamente com a flexibilidade e o rigor necessário, isto é, apoiando suas ações em uma fundamentação válida para evitar cair no paradoxo de ensinar e não ensinar.

A busca pela continuidade do processo de formação profissional, tendo como referência a complexidade da tarefa educativa do professor, o contexto de transformações sociais e, sobretudo políticas educacionais que se renovaram nos últimos anos, especialmente em relação à educação inclusiva, aponta a necessidade de uma formação continuada. Para Almeida (2008), a formação continuada refere-se a um conjunto de atividades desenvolvidas ao longo da carreira docente em diversos espaços educacionais.

As universidades são um "espaço privilegiado para essa formação, por serem locais de avanço científico e profissional" (MIZUKAMI et al. 2006, p. 27). O ambiente da formação pode ser concebido como um lugar de grande impacto para a transformação, segundo Candau (1996, p. 143) contudo, a autora defende a ideia de que o local deve ser no mesmo ambiente de sua profissionalização, ou seja, "é preciso deslocar o lócus da formação continuada de professores da universidade para a própria escola".

A formação continuada refere-se ao "processo de desenvolvimento da competência dos educadores, aqueles que têm como ofício transmitir - criando e reproduzindo o conhecimento histórico e socialmente construído por uma sociedade" (FUSARI; RIOS, 1995, p. 40). Tendo como pressuposto que se vive numa sociedade em que novos paradigmas educacionais emergem constantemente, os autores sugerem que a educação continuada deva estar inserida nas atribuições das políticas públicas e que devem ocupar-se de estratégias para capacitar os educadores, favorecendo a adequação pedagógica sempre que necessário. 
A formação continuada é a oportunidade de (re) construção permanente de uma identidade pessoal do professor; este processo não deriva de informações recebidas por cursos de conhecimentos e técnicas, porém, sobretudo, em momentos de reflexões críticas a respeito das práticas pedagógicas adotadas (Nóvoa (2009). Nesta perspectiva é que a Associação Nacional pela Formação de Profissionais da Educação (ANFOPE) (apud BITTENCOURT, 2006, p. 71) discorreu sobre o tema:

\begin{abstract}
A formação continuada é uma das dimensões importantes para a materialização de uma política global aos profissionais da educação, articulando à formação inicial e à condição de trabalho, salário, carreira e deve ser entendida como continuidade da formação profissional, proporcionando novas reflexões sobre a ação profissional e novos meios para desenvolver e aprimorar o trabalho pedagógico; um processo de construção permanente do conhecimento e desenvolvimento profissional, a partir da formação inicial e vista como uma proposta mais ampla, de hominização, na qual o homem integral, omnilateral, produzindo-se a si mesmo, também se produz na interação com o coletivo (ANFOPE, 1998).
\end{abstract}

Contudo, a formação inicial não é suficiente para preparar o professor, conforme as especificidades que o sistema educacional exige, pois, ao exercer sua atividade como profissional da educação, novos paradigmas são propostos em legislações, demandando novas metodologias e, consequentemente, aprimoramento na formação.

Desde a inserção da Educação Inclusiva no sistema educacional, os cursos de formação continuada tornaram-se imprescindíveis, para fundamentar e habilitar o professor nas diversas facetas que compreendem o processo de inclusão: as políticas públicas implantadas, a diversidade das características individuais dos alunos com deficiências, as concepções frente à inclusão, a organização do currículo, as estratégias e recursos pedagógicos a serem empregadas, a avaliação e intervenção educacional entre outros (HUMMEL, 2015).

Como forma de garantir o aprimoramento do professor após seu egresso da formação inicial e, ainda, para aqueles que exercem sua atuação pedagógica no âmbito escolar, diversos cursos são organizados, visando atender a demanda destas necessidades de formação docente.

A Resolução no 4 de 02/10/2009, no Art. 12, (p. 3), ressalta a importância da formação de profissionais que atuam no $\mathrm{AEE}$ ao afirmar que "o professor deve ter formação inicial que o habilite para o exercício da docência e formação específica para a Educação Especial" (BRASIL, 2009). A formação proposta é bastante genérica; ela por si só não garante que o professor egresso esteja totalmente preparado para atuar com alunos com deficiências.

O reflexo da formação inicial faz com que o professor busque uma complementação por meio de cursos de pós-graduação ou mesmo de capacitação em serviço, o que, de certa forma, ainda não supre as reais necessidades para sua atuação no AEE. Podese inferir que a formação inicial se caracteriza como generalista, haja vista que os 
programas curriculares propostos nos cursos de licenciatura ainda deixam lacunas na formação dos professores. A complexidade que envolve o conhecimento a respeito da temática deficiências leva a crer na necessidade de formação que contemple os aspectos necessários para o desempenho de uma prática realmente inclusiva (HUMMEL, 2015).

Tendo como pressuposto que o professor responsável pela atuação no AEE necessita de uma formação específica nesta área de atuação, e visando a formação continuada dos professores, a Secretaria Municipal de Educação de Londrina, Estado do Paraná, Brasil, iniciou no ano de 2017 uma proposta de formação em grupos colaborativos, tendo em vista que esta abordagem "reconcilia duas dimensões da pesquisa em educação, construção dos saberes e a formação contínua dos professores” (IBIAPINA, 2008, p. 21).

\section{DESENVOLVIMENTO}

A rede municipal de educação de Londrina, oferta a educação infantil e o ensino nas séries iniciais. Contando com 74 escolas na zona urbana, 13 escolas na zona rural e 34 centros de educação infantil. Em 44 escolas estão instaladas as salas de recursos mulfuncionais que ofertam o AEE nas salas de recursos multifuncionais. Possuindo um setor denominado Gerência de Apoio Educacional Especializado (GEAE). Este setor forma-se por uma equipe multidisciplinar composto por: psicopedagogos, psicólogos, doutoras em educação, mestre em educação e psicologia, que assessoram os professores do AEE. Dentre as atribuições dos assessores está a oferta de formação continuada que tem como objetivo propiciar aos professores do AEE um espaço para estudo e reflexões a respeito da sua prática educacional.

Visando a formação continuada dos professores do AEE, a Gerência de Apoio Educacional Especializado iniciou no ano de 2017 uma proposta de formação em grupos colaborativos, pois esta abordagem "reconcilia duas dimensões da pesquisa em educação, construção dos saberes e a formação contínua dos professores" (IBIAPINA, 2008, p. 21). A metodologia colaborativa, ainda, pode assegurar uma relação dialética teoria e prática, e reforçar a importância de os professores constituírem grupos de estudos para que no coletivo adotem uma postura investigativa, questionadora e transformadora de suas práticas, na medida que a formação se volta para a resolução das dificuldades enfrentadas, e principalmente, aqueles vivenciados durante o AEE.

A formação em grupos colaborativos consistiu em encontros mensais com os professores do AEE e foi planejada em etapas. As etapas consistiram em: 1) Diagnóstico das demandas; 2) Encontros teórico-reflexivo; 3) Avaliação dos resultados.

Neste sentido, apresenta-se a seguir o desenvolvimento de cada etapa da formação, assim como os resultados e análises levantadas. 


\section{Etapa 1 - Diagnóstico}

O primeiro momento da formação caracterizou-se como diagnóstico das demandas que as professores de AEE possuíam durante sua prática com os alunos com Necessidades Educacionais Especiais (NEE) em SRM. As professoras responderam um questionário informando os temas que gostariam que fossem trabalhados. As demandas registradas pelas professoras como necessidade de aprofundamento foram referentes aos seguintes temas: Deficiências e transtornos, Intervenção pedagógica, Avaliação, Altas Habilidades, Alfabetização e Matemática.

Para identificar o perfil das professoras, as mesmas responderam um questionário, no Google Form, que resultou nas informações a respeito da formação acadêmica e tempo de experiências profissional, a saber: 1) Formação Acadêmica: 79\% possuem Pedagogia, as demais licenciaturas diversas; 2) Formação latu-sensu: todas possuem formação na área da educação especial; 3) Formação stricto-sensu: quatro professoras qualificadas como mestres em educação; 4) Tempo de Magistério: 35,9\% classificaram entre 16 a 25 anos de atuação no magistério, enquanto $47 \%$ entre 5 a 15 anos; 5) Tempo de experiência nas salas de recursos multifuncionais: 41,3\% atuaram entre 3 a 5 anos, 36\% entre 0 a 2 anos e 9,5\% de 6 a 8 anos; 6) Experiência em outros tipos de atendimento especializado: $68 \%$ nunca atuaram e $31,7 \%$ tinham experiência com desenvolvimento de suas atividades em escolas ou instituições especiais, em setores clínicos psicopedagógicos e apoio de alunos.

Estas informações foram imprescindíveis para que a equipe do GEAE, conhecesse o perfil das professoras do AEE, principalmente em relação a sua experiência com os alunos com NEE. Os resultados revelaram que algumas professoras possuíam pouca experiência, sendo necessário uma assessoria in loco que fortalecesse e subsidiasse o trabalho da professora de AEE no atendimento aos alunos.

Ainda, naquela etapa foi fundamental para que a equipe pudesse debater a metodologia a ser adotada nos encontros teóricos-reflexivos, tendo em vista o atendimento das demandas apontadas.

\section{Etapa 2-Encontros teórico-reflexivo}

A partir das demandas levantadas foram eleitas pelas participantes, como necessidade de melhor compreensão, os temas: Avaliação e intervenção psicoeducacional no contexto escolar; Alfabetização na rede municipal de educação de Londrina; Compreensão do processo de alfabetização em língua portuguesa na rede Municipal de Educação de Londrina; Aprendizagem em matemática na rede Municipal de Educação de Londrina e Compreensão do processo da aprendizagem em matemática na rede Municipal de Educação de Londrina. Os temas propostos caracterizaram o referencial teórico inicial para as discussões posteriores nos encontros teóricos.

Com base no delineamento apresentado, optou-se pela realização de encontros mensais para a discussão acerca dos temas apontados. Nos encontros foram discutidas 
diagnóstico do aluno e intervenções educacionais a serem aplicadas, também, a troca de experiências enriqueceu fortemente o trabalho. Ressalta-se que os grupos de discussões foram formados pelas professoras do AEE e assessoras da Gerencia de Apoio Educacional Especializado, que exerceram o papel de formadoras. Além dos encontros em grupos, mensais, foram planejadas três palestras, durante o ano com todos os componentes do grupo, com profissionais especializados na temática abordada nos estudos.

Concomitante ao debate teórico, foi utilizado um ambiente virtual de aprendizagem, plataforma Moodle, onde foram disponibilizados os materiais teóricos e atividades de interação e troca de conhecimento entre as participantes, como fórum de discussões.

O primeiro encontro se deu a partir da indicação das professoras do AEE de um estudo de caso de um aluno atendido na SRM. Para a seleção adotou-se o seguinte encaminhamento, cada professora selecionou um estudo de casos com base nas avaliações do contexto já realizadas pelas mesmas. Este procedimento foi atrelado à possibilidade de se obter dados fornecidos pelos próprios participantes a respeito do discurso pedagógico cotidiano que utilizam e que direciona a atuação no âmbito escolar.

Para o estudo do caso, as professoras seguiram um roteiro norteador que constava elementos como: 1) Identificação: composição e dados familiares; informação escolar; 2) Avaliação Geral: dados relevantes pré, peri e pós-natal e de desenvolvimento atual; âmbito familiar; âmbito escolar; 3) Avaliação do Aluno: condições de saúde geral; Necessidades educacionais especiais do aluno; Desenvolvimento do aluno: função cognitiva, atenção, memória; linguagem, raciocínio lógico, função motora; função pessoal e social. A atividade proporcionou uma maior compreensão dos aspectos que devem ser considerados na avaliação de um aluno com NEE.

A referida atividade foi realizada e disponibilizada no Ambiente Virtual de Aprendizagem para que seu grupo tivesse acesso e pudessem eleger um estudo de caso que propiciasse uma maior análise com base na teoria pertinente, desta forma possibilitou a interação entre as professoras na seleção de um estudo de caso que subsidiou o planejamento dos encontros teóricos reflexivos subsequentes.

Os demais encontros, foram organizados seguindo o mesmo procedimento metodológico, ou seja, com estudos de casos, leituras teóricas, atividades interativas virtuais, palestras e troca de experiências.

Para conhecer o grau de satisfação das professoras, em relação a esta nova proposta de formação continuada, grupos colaborativos, foram feitas avaliações ao final de cada encontro. Assim, a equipe do GEAE analisava os aspectos que deveriam ser aprimorados. $\mathrm{O}$ modelo de formação colaborativa foi apontado positivamente pelas professoras, como se observa nos relatos abaixo. 
A forma do curso está muito boa, uma vez que a forma colaborativa, temos que aprender para discutir com os pares. (S.G)

Este formato de estudo está sendo de grande valia, pois aprendemos, compartilhamos e trocamos experiências. $\mathrm{O}$ conteúdo está bem interessante e pertinente ao nosso trabalho. Aprende muito e isto me auxilia no meu fazer pedagógico junto aos alunos com SRM. (M.J.D)

Esse novo formato das formações está sendo bem produtivo, a troca de conhecimentos e experiências tem acrescentado muito à nossa prática em sala de aula. Os temas abordados atendem nossas necessidades e nos levam a refletir sobre nossos conceitos e prática pedagógica. (E.B.A)

Tenho achado bem interessante esse novo estilo de trabalho. Os temas, os textos pertinentes e fácil linguagem e compreensão. Quando há interação "colaborativo" como está sendo, há um melhor aprendizado e troca de experiências. (D. Z)

Quanto a participação nas atividades virtuais e presenciais, as professoras do AEE, responderam um questionário no modelo da Escala Likert. Participaram das avaliações 67 professoras que responderam como a atividade no fórum contribuiu para ampliar seus conhecimentos. Os resultados apresentam dados significativos, conforme observase no gráfico 1.

\section{Gráfico 1: Atividades virtuais}

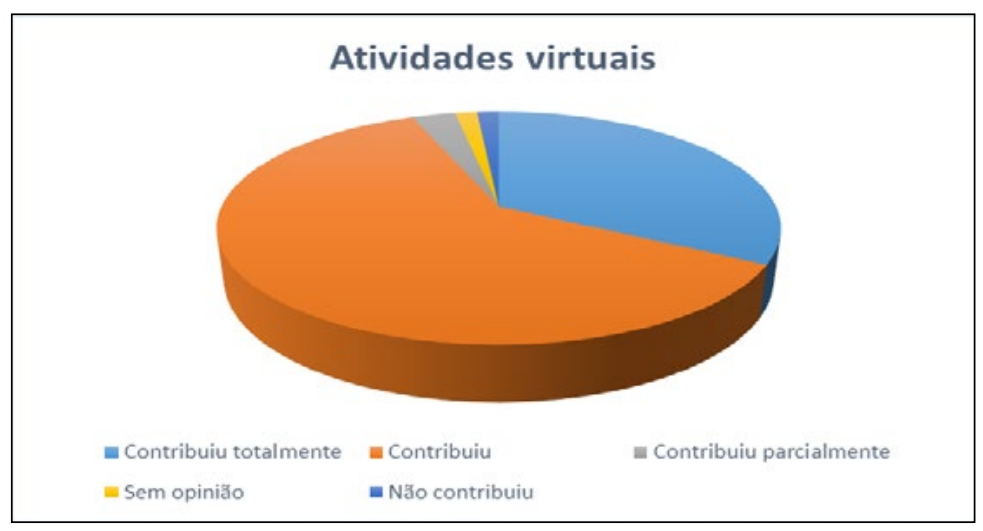

Fonte: As autoras.

Os resultados demonstraram que 22 professoras afirmaram que a atividade virtual contribuiu totalmente; já para 41 contribuiu, enquanto que para 2 professores contribuiu parcialmente. Os indicadores sem opinião e não contribuiu também foram informados por 2 professoras, pode-se inferir que a opção assinada correspondeu ao número de professores que não realizaram a atividade proposta no Fórum.

Quanto aos resultados dos encontros teóricos reflexivos, ou seja, as atividades presenciais, para 48 professoras os estudos contribuiram totalmente; 17 professoras informaram que contribuiu; e para 2 professoras contribuiu parcialmente. 


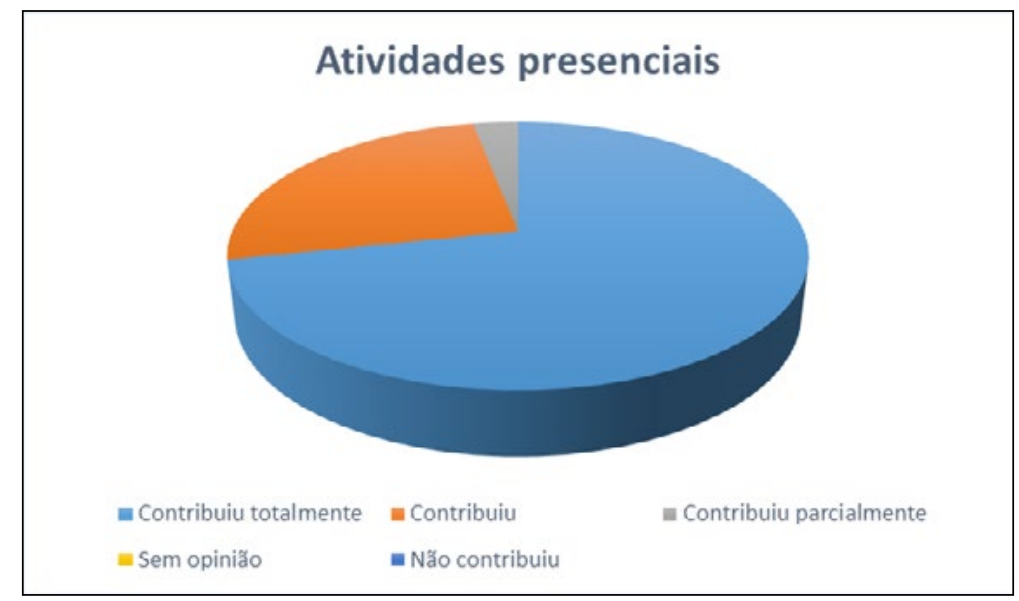

Fonte: As autoras.

Conforme observa-se nos gráficos acima, a proposta de formação em grupos colaborativos demonstrou resultados positivos. As professoras, ainda, apontaram comentários, críticas e sugestões. A seguir algumas das respostas das professoras.

P2- Achei ótimo o encontro muito esclarecedor. E apesar de muitas dúvidas surgirem no nosso cotidiano, seria muito bom que falássemos também de medidas de intervenção com mais ênfase.

P8- Material muito bom, textos que ajudaram a ampliar o conhecimento. O estudo colaborativo tem ajudado muito. $\mathrm{O}$ conhecimento e prática de cada professora são ricos.

P10 - Este tipo de estudo estimula o debate sobre temas estudados anteriormente e situações vivenciadas no nosso cotidiano de SRM.

P12- Os estudos estão sendo ótimos para meu crescimento. A sugestão é que continue assim.

P23- Foi muito produtivo, pois precisamos dessas experiências e trocas para aperfeiçoar o nosso trabalho. Essa formação deveria ser passada a todos os professores da rede.

P24- Os estudos são ótimos e sempre necessários para nosso conhecimento, a troca de experiências nos levam sempre a reflexões onde buscamos novas estratégias e estudos para a nossa profissão.

P26- Avalio que tanto as discussões desenvolvidas no grupo, bem como as atividades práticas (dinâmica de grupo) possibilitaram maiores discussões e trocas de conhecimentos.

P34- Acho sempre valida toda troca e estudos que foram proporcionadas. A equipe sempre prestativa e comunicativa, auxiliando na complementação e discussão dos temas, contribuindo diretamente nas avaliações psicoeducacionais, bem como nos atendimentos da SRM.

P56- A estratégia utilizada de estudo colaborativo tem sido de melhor aproveitamento. 
As informações registradas pelas professoras demonstraram que o diálogo estabelecido no modelo de uma formação colaborativa tem favorecido uma maior compreensão sobre as temáticas relacionadas as deficiências. Na medida em que são elucidadas as dúvidas, por meio do embasamento teórico e discussões práticas. Neste modelo de formação continuada todos os envolvidos, professores do AEE e assessorias da secretaria municipal de educação são responsáveis pelo desenvolvimento desta proposta.

\section{Etapa 3 - Avalią̧ão dos resultados}

Esta etapa consistiu na culminância dos estudos teóricos-reflexivos e da prática do AEE que ocorreu na $1^{\text {a }}$ Mostra de trabalhos das salas de recursos multifuncionais. As professoras selecionaram um caso de aluno atendido no AEE, elaboraram e aplicaram o plano de educacional especializado, e expuseram o trabalho na modalidade comunicação oral e pôster.

Ao serem questionadas a respeito da culminância em formato de estudo de casos, correlacionando os estudos teóricos ocorridos ao longo do ano, as professoras responderam que:

P1- A mostra foi em um formato em que tivemos a oportunidade de observar e trocar informações e experiências, isso foi muito válido.

P2- Pensar em como expor o que realizamos em atendimento e fundamentar com teoria ajudou na reflexão. Acredito que no ano de 2018, esta Mostra deveria ser com toda a rede, assim as professoras regentes de sala de aula poderiam entender melhor nosso trabalho.

P3- O fato de poder conhecer a pratica das colegas relatada de maneira tão ilustrada ampliou meu conhecimento e inclusive trouxe novas ideias para a prática do AEE, muito bom mesmo. $O$ fato de expor, trouxe também dentro da escola um reconhecimento pelo trabalho realizado, muito importante.

Observou-se nos registros das professoras que a formação continuada em questão, enriqueceu o conhecimento com novas aprendizagens e estratégias que podem ser somadas às práticas das professoras de $\mathrm{AEE}$, na medida em que as mesmas participaram efetivamente da formação não apenas como expectadoras, mas como autoras e corresponsáveis por cada um dos encontros teóricos-reflexivos.

\section{CONCLUSÃO}

A Rede Municipal de Educação de Londrina, mais especificamente a GEAE, tem vivenciado uma nova forma de atuar na formação dos professores do AEE. Os grupos colaborativos utilizados proporcionaram a formação contínua destes professores na construção de seus saberes.

O trabalho colaborativo fez a diferença na atuação dos professores por estar totalmente vinculada a necessidade apontada pelo grupo. A teoria selecionada 
para subsidiar a reflexão, atendeu as necessidades apontadas, proporcionando uma ação com maior reflexão. Fatos esses observados mediante os relatos decorrentes da participação dos professores, quanto a ressignificação da prática vivenciada em SRM e das experiências didáticas utilizadas para a sistematização de ações direcionadas a dificuldades de aprendizagem apresenta das pelos alunos de AEE.

Acredita-se que este modelo de formação contribuiu significativamente na construção de novos saberes, refletindo na atuação prática das professoras durante o atendimento educacional especializado. A disseminação deste modelo de formação pode ser aplicada em diversas áreas de conhecimento da educação, promovendo uma nova forma de investimento na formação docente.

\section{REFERÊNCIAS}

ALMEIDA. G.P. A construção de ambientes educativos para a inclusão. Curitiba: PróInfantil.2008.

ANFOPE. Associação Nacional pela formação dos profissionais da educação. Documento final IX. Campinas, 1998.

AZANHA, J. M. P. A formação do professor e outros escritos. São Paulo: Senac. 2006.

BAPTISTA, C. R. Ação pedagógica e educação especial: para além do AEE. In: IV Seminário Nacional de Pesquisa em Educação Especial, 2011.

BITTENCOURT, A, B. Sobre o que falam as coisas lá fora: formação continuada dos profissionais da educação. In: FERREIRA, N. S. C. (Org.). Formação Continuada e Gestão da Educação. 2. ed. São Paulo: Cortez, 2006.

BRAGA, D. R. (2009). Formação Inicial de Professores e Educação Especial. 32a Reunião Anual da ANPED - Sociedade, cultura e educação: novas regulações? Caxambu, 4-7 de outubro de 2009. Caxambu: ANPED. Disponível em http://www.anped.org.br/reunioes/32ra/ arquivos/trabalhos/GT08-5205Int.pdf. Acesso em 15 de setembro, 2017.

BRASIL. Política Nacional de Educação Especial na Perspectiva da Educação Inclusiva. (2008). Brasil. Ministério da Educação. Secretaria de Educação Especial, Brasília. Disponível em: http://portal.mec.gov.br/arquivos/pdf/politicaeducespecial.pdf. Acesso em: 07 jul. 2017.

BRASIL. Resolução n. 4, de 2 de outubro de 2009. Diretrizes Operacionais para o Atendimento Educacional Especializado na Educação Básica, modalidade Educação Especial. Brasília: Diário Oficial da União, n. 190, Seção 1, p. 17, 05.

BRASIL. Resolução CNE/CP 1, de 18 de Fevereiro de 2002. Institui Diretrizes Curriculares Nacionais para a Formação de Professores da Educação Básica. Brasília. Disponível em: http://portal.mec.gov.br/cne/arquivos/pdf/CP012002.pdf. Acesso em: 10 de ago. 2017. 
CANDAU, V. M. C. Formação continuada de professores: tendências atuais. In: Reali, A. M. M. R.; MIZUKAMI, M. G. N. (Orgs.). Formação de Professores: tendências atuais. São Carlos: EdUSFCAR, 1996.

COLL, C.; MARCHESI, A; PALACIOS, J. Desenvolvimento psicológico e educação 3 -Transtornos do desenvolvimento e necessidades educativas especiais. 2. ed. Porto Alegre: Artmed, 2004.

FONSECA-JANES, C. R. A formação dos estudantes de Pedagogia para a educação inclusiva: estudo das atitudes sociais e do currículo. Tese (Doutorado em Educação) Universidade Estadual Paulista Júlio de Mesquita Filho, Marília, 2010.

FUSARI, J. C.; RIOS, T. A. Formação continuada dos profissionais do ensino. Cadernos CEDES, Campinas, 1995.

GARCIA, R. M. C. Política Nacional de Educação Especial nos anos 2000: a formação de professores e a hegemonia do modelo especializado. In BAPTISTA, C. R.; CAIADO, K. R. M.; JESUS, D. M. Professores e Educação Especial: formação em foco. Porto Alegre: Mediação, 2011.

HUMMEL, E. I. A formação de professores para o uso da informática no processo de ensino e aprendizagem de alunos com necessidades educacionais especiais em classe comum. Dissertação (Mestrado em Educação) - Universidade Estadual de Londrina, 2007.

Formação de professores de salas de recursos multifuncionais para o uso da tecnologia assistiva. Tese (Doutorado em Educação) Universidade Estadual Paulista Júlio de Mesquita Filho, Marília, 2012.

IBERMÓN, F. Formação docente e profissional: formar-se para a mudança e a incerteza. São Paulo, Cortez, 2000.

IBIAPINA, I. M. L. de M. Pesquisa colaborativa: investigação, formação e produção de conhecimentos. Brasília: Líber Livro, 2008.

MAGALHÃES, M. C. C. (Org.). A formação do professor como um profissional crítico: Linguagem e Reflexão. Campinas, SP: Mercado das Letras, 2004.

MARQUEZINE, M. C. Formação de profissionais/professores de Educação Especial Deficiência Mental e Curso de pós-graduação lato sensu: um estudo de caso. Tese (Doutorado em Educação) - Universidade Estadual Paulista "Júlio de Mesquita Filho", Faculdade de Filosofia e Ciências, Marília, 2006.

MESQUITA, A. M. A. A formação inicial de professores e a educação inclusiva: analisando as propostas de formação dos cursos de licenciatura da UFPA. Dissertação (Mestrado em Educação) - Universidade Federal do Pará. Belém, 2007.

MICHELS, M. H. O Instrumental, o Generalista e a Formação à distância: estratégias para a reconversão docente. In: BAPTISTA, C. R.; CAIADO, K. R. M.; Jesus, D. M. Professores e Educação Especial: formação em foco. Porto Alegre: Mediação, 2011.

MIZUKAMI, M. G. et al. A escola e Aprendizagem da Docência: Processos de Investigação e Formação. São Carlos: EduFSCAR, 2006. 
NÓVOA, A. Para uma formação de professores construída dentro da profissão. In: NÓVOA, A. Professores: imagens do futuro presente. Lisboa: Educar, 2009.

PERRENOUD et al. Formando Professores Profissionais: Quais estratégias?

RIBEIRO, M. J. L. Formação de professores: conhecendo as formas de organização curricular das especializações e as necessidades do professor para a prática de uma educação inclusiva. Tese (Doutorado em Educação) - Universidade de São Paulo, São Paulo, 2005.

SCHÖN, D. Os professores e sua formação. Lisboa: Dom Quixote, 1997.

SILVA, L. C. Políticas públicas e formação de professores: vozes e vieses da educação inclusiva. Tese (Doutorado em Educação) - Universidade Federal de Uberlândia, 2009.

STAINBACK, W.; STAINBACK, S. Um guia para educadores. Porto Alegre: Artes médicas Sul, 1999.

TARDIF, M. Saberes docentes e formação profissional. Petrópolis: Vozes, 2007

VITALIANO, C. R. (Org.). Formação de professores para inclusão de alunos com necessidades educacionais especiais. Londrina: EDUEL, 2010.

VITALIANO, C. R.; MANZINI, E. J. A formação inicial de professores para inclusão de alunos com necessidades educacionais especiais. In: VITALIANO, C. R. (Org.). Formação de professores para inclusão de alunos com necessidades educacionais especiais. Londrina: EDUEL, 2010. 